\title{
LA RIQUEZA ESPECULATIVA \\ DE LA ESCUELA DE SALAMANCA
}

\author{
Juan Cruz Cruz \\ Universidad de Navarra \\ jcruz@unav.es
}

\section{i. Presentación}

La investigación que desde hace tiempo he realizado sobre la Escuela de Salamanca, en los siglos XVI y XVII, pretende estudiar y dar a conocer aquellas categorías filosóficas que, presentes en la actualidad, fueron ya discutidas y profundizadas interdisciplinarmente por la Escuela de Salamanca con un rigor altamente sistematizado.

\section{EXIGENCIA METÓDICA}

Ahora bien, en cualquiera de los temas que se estudian, he querido que la mirada de investigador no se detuviera puntualmente en la época aureosecular; hay que dirigirla también, por un lado, a la filosofía anterior que inspiró y proporcionó al Siglo de Oro temas de excepcional interés, y, por otro, a la filosofía contemporánea, heredera de un importante legado de reflexión en áreas como la metafísica, la lógica, la antropología, la filosofía jurídica y política, filosofía moral, etc. Y ello, dentro de un enfoque comprensivo, que atienda a una exigencia metódica fundamental, a saber: es preciso tener una clara perspectiva histórica, para entender mejor las tesis de los grandes pensadores de la Escuela de Salamanca, y no confundirlas con sus deformaciones ulteriores. Asimismo, un estudio abierto, sin prejuicios, de los pensadores de la Escuela de Salamanca debe evitar la caricatura de una época atrincherada en temas teológicos; pues basta comprobar que también se abrió a la lógica, a la filosofía del lenguaje, a la antropología, a la epistemología y a la ética.

\section{Disciplinas IMPORTANTES}

Mi proyecto personal sobre el Siglo de Oro español pretende resaltar las aportaciones de los maestros de la Escuela de Salamanca, destacando el interés de sus planteamientos en distintas áreas, de las que sólo voy a indicar algunas:

I. Filosofía politica: La Escuela de Salamanca destaca temas nuevos concernientes a la teoría de los derechos y libertades, del poder y de la guerra (Francisco 
de Vitoria, Francisco Suárez). Con Vitoria se formula una articulación jurídicomoral presidida por tres principios básicos: el derecho fundamental de los nativos del Nuevo Mundo a ser hombres y ser tratados como seres libres; el derecho fundamental de sus pueblos a tener y defender su propia soberanía; y el derecho fundamental del orbe a hacer y colaborar en bien de la paz y solidaridad internacional (véase Cruz 2009).

2. Derecho penal: la Escuela de Salamanca supo diferenciar tanto teológica como canónica y jurídicamente los aspectos preventivos, disuasivos, satisfactorios y de mero castigo de la pena, buscando fundamentos aceptables de justificación y evitando el peligro de elaborar un derecho penal deshumanizado (Martín de Azpilcueta, Alfonso de Castro). Los maestros del siglo XVI y XVII estimaron que la justicia penal no es una parte de la justicia distributiva — pues las penas no son un depósito de males para ser distribuidas-, sino de la conmutativa: la pena es un sufrimiento que se inflige observando una igualdad con el delito. Es con Martín de Azpilcueta y principalmente con Alfonso de Castro cuando nace en Europa por vez primera una teoría abarcadora del derecho penal.

3. Filosofía de la economía: En varios maestros de la Escuela de Salamanca comparecen planteamientos propios acerca del mercado, del interés y de las instituciones económicas (Vitoria, Soto, Covarrubias, Tomás de Mercado, Martín de Azpilcueta). Y aunque casi siempre aquellos maestros hablaron como moralistas, aportaron también interesantes matices a la teoría económica, como el análisis del dinero y de la realidad comercial, la fijación del justo precio, la formación de compañías comerciales, la conveniencia de los seguros de vida y navegación. La Escuela de Salamanca aporta especialmente la formulación de una teoría psicológica —o subjetiva - del valor aplicada tanto a los bienes como al dinero: el valor de un artículo no dependería de su naturaleza esencial, sino de la estimación de los hombres, incluso si dicha estimación fuera imprudente, estando la estimación determinada por las fuerzas de la oferta y la demanda.

4. Filosofía del derecho: Varios maestros de la Escuela de Salamanca estudiaron la esencia de la ley y del derecho en sendos tratados, basados casi todos ellos en uno primero que escribió Soto, titulado De iustitia et iure. Por ejemplo, Báńez escribe De Iustitia et Iure para explicar no sólo la esencia del derecho y la naturaleza de la justicia, sino también para resaltar aspectos importantes que no habían sido suficientemente tratados, como la explicación de la epiqueya o reconducción práctica de las leyes humanas a la ley natural, hasta tal punto que la epiqueya se constituye como el acto principal de la justicia legal y sin él queda toda la teoría de la justicia en el aire (véase Cruz 2008b). También como prolongación de la obra de Soto escribió Francisco de Araújo Las leyes, donde el autor ofrece una profunda reflexión ontológica sobre la esencia de la ley, especialmente sobre la ley 
natural y su proyección sobre el conjunto de las leyes, tanto civiles como penales. El tratado sobre Las leyes de Araújo refleja el sentir gnoseológico, ontológico y moral de la Escuela de Salamanca sobre esta materia, y se puede decir que culmina la pretensión que un siglo antes tuvo Vitoria (véase Cruz 20Io).

Un punto de suma actualidad filosófico-jurídica, presente en los tratados $D e$ iustitia et iure, es el del "reconocimiento" (Anerkennung), estudiado a propósito del honor y la fama, dentro de la justicia conmutativa. El honor era entendido en la Escuela de Salamanca precisamente como "recognitio". Y la ofensa al "honor" era un título suficiente de beligerancia intragrupal o supragrupal. La argumentación sobre el honor tiene su fundamento psicológico en el hecho de que el honor surge del profundo deseo humano de "reconocimiento", vigente y actuante en todos los seres humanos de todos los tiempos. Así lo había indicado ya Luis de Molina en su tratado De iustitia et iure, al definir el honor como "la manifestación [de algo] que se le hace a una persona en testimonio y reconocimiento de sus valores o de una excelencia suya" (De iustitia et iure, I593, tomo IV, disput. I, n.I. Estoy preparando la versión castellana de este tratado).

5. Metafísica: Los maestros de la Escuela de Salamanca abordan un estudio profundo de la teoría del acto de ser, la esencia y los transcendentales (Domingo Báñez, Pedro de Ledesma, Suárez, Juan Poinsot). El esclarecimiento que, por ejemplo, Báñez y Ledesma hacen del "ser como acto" (actus essendi) es una exégesis precisa y profunda que valora la repercusión de la actualidad del ser en los diversos ámbitos de la filosofía: ontología, psicología, gnoseología, moral, etc. Este mérito hace que las obras de estos maestros sean acreedoras de una atención especial, máxime cuando Cornelio Fabro indicara que la Escuela de Salamanca había producido un "oscurecimiento" de la actualidad del ser. Ya Gilson advirtió, frente a Fabro, que Báńez, por ejemplo, explica con claridad la actualidad del ser, en la que se apoya la doctrina de la participación (véase Cruz 2008a).

6. Antropología cultural: Maestros y discípulos de la Escuela de Salamanca producen estudios dirigidos a comprender los nuevos pueblos y culturas descubiertos en el Nuevo Mundo, con sus costumbres propias y su vida religiosa. Bartolomé de las Casas fue, por su investigación de las costumbres, creencias y organización política de los nativos del Nuevo Mundo, un señalado antecedente de Lévy-Bruhl y Lévi-Strauss.

7. Teología: Son conocidas las aportaciones de la Escuela de Salamanca a la Eclesiología y a la doctrina de la fe, al influjo de la gracia, cuya incidencia en la voluntad humana acarreó un hercúleo debate, llamado "De auxiliis", con repercusiones en toda Europa, apareciendo de modo especial en la metafísica (con Báñez, Guevara, Pedro de Aragón y Molina). 
8. Psicología de la mistica: Aquellos maestros salmantinos resaltan las condiciones psicológicas de posibilidad del acto místico en el hombre, según los planteamientos de San Juan de la Cruz y de Santa Teresa (cfr. Tomás de Jesús y Salmanticenses); se enfocan aquellos actos anímicos o espirituales ligados a la contemplación mística y se estudia el significado de una experiencia inmediata y sustancial de la divinidad en el interior del alma humana (véase Cruz 2012). Puntos que fueron destacados luego por Bergson y Max Scheler y articulados también en algunos escritos de Edith Stein.

9. Epistemología: Para los maestros de la Escuela de Salamanca, el problema del conocimiento está motivado por la pregunta acerca de la esencia de la verdad, la cual se muestra formalmente como una relación (llamada globalmente relación veritativa; véase Cruz 2002), donde se dan cita también la relación creatural (la verdad en su fuente) y la relación sígnica (la verdad en su manifestación enunciativa; véase Cruz 2000); como modo de la relación veritativa, en lo concerniente a la verdad práctica, es considerada la relación moral. Pero la aclaración de estas relaciones exige también hacerse cargo de la relación en sí misma. La analítica de la relación, presente ya en la época medieval, permite distinguir dos ámbitos de relación: el ideal y el real. Y entre las relaciones reales cabe diferenciar las categoriales y las trascendentales.

Io. Lógica: En la Escuela de Salamanca se replantea el alcance del conocimiento humano en su relación con la ciencia moderna incipiente (por ejemplo, Soto, Sebastián Izquierdo o Juan Caramuel). Y abordaron los aspectos centrales del pensamiento realista que el nominalismo tardo-medieval había dejado oscurecidos (Domingo de Soto, Domingo Báńez). Los maestros de la Escuela de Salamanca enfocaron la lógica y su objeto desde el punto de vista de la "intencionalidad". Para ellos lo intencional es un fenómeno que abarca toda la vida del sujeto, tanto la inconsciente como la consciente, tanto la teórica como la práctica (véase Cruz 2006).

\section{Conclusión}

Para terminar, $-\mathrm{y}$ aunque ni siquiera he pretendido abarcar todos los puntos doctrinales fundamentales de la Escuela de Salamanca- considero importante recordar la exigencia metódica propuesta al principio: nuestro estudio de la Escuela de Salamanca debe integrar las perspectivas y los resultados de la investigación histórica actual, sin excluir una reivindicación de orden filosófico, lo cual implica considerar con seriedad los varios siglos de tradición precedentes; si no fuese así, los trabajos de este proyecto se convertirían en una empresa ideológica al servicio de una posición preconcebida. De la doctrina de cada pensador de la Escuela de Salamanca es necesario distinguir las raíces, el tronco, las ramas y las 
hojas: no todas las dimensiones doctrinales están en un mismo plano, ni tienen igual valor, ni siquiera filosófico; aunque, por otra parte, cada pensador no ofrezca un conglomerado o agregado de teorías, sino un organismo doctrinal. De todo lo que estos maestros enseñan, debe discernirse lo que es principal o fundamental, lo que es explicativo, lo que es circunstancial e incluso lo que estaba condicionado históricamente. El papel de la crítica interna y del estudio histórico ha de incluirse en la lectura de cada organismo doctrinal.

De esta exigencia metódica se sigue que inevitablemente el investigador actual interrogue al pasado desde los problemas de su presente histórico. Debería ocurrir entonces que, por ejemplo, Vitoria, Soto o Suárez aparezcan como lo que fueron: autores "abiertos" que hoy pueden ser leídos de tal modo que permitan, en cada caso, una rehabilitación específica de sus enseñanzas.

Con esta exigencia metódica, debemos intentar alcanzar el mejor conocimiento del texto mismo de cada autor estudiado: incluso las ediciones de tales textos han de incorporar los resultados de la crítica y de la bibliografía competente; también debe procurarse el mejor conocimiento del contexto institucional (universitario, social, etc.), y no sólo el doctrinal (aristotelismo, agustinismo, etc.), en que semejantes doctrinas surgieron.

\section{REFERENCIAS}

Cruz Cruz, J., Juan Poinsot: El Signo, Pamplona, 2000.

Cruz Cruz, J., Juan Poinsot: Verdad Transcendental y Verdad Formal, Pamplona, 2002.

Cruz Cruz, J., y SÁnchez Sedeño, J, Las Segundas Intenciones y el Universal, Pamplona, 2006.

Cruz Cruz, J., Creación, Signo y Verdad, Pamplona, 2008.

Cruz Cruz, J., Domingo Báñez: El Derecho y la Justicia, Pamplona, 2008.

Cruz Cruz, J., Fragilidad Humana y Ley Natural, Pamplona, 2009.

Cruz Cruz, J., Francisco Araújo, Las Leyes, Pamplona, 2010.

Cruz Cruz, J., Neoplatonismo y Mistica: La contemplación en Tomás de Jesús (s. XVI), Pamplona, 2012. 